\title{
A case of coxsackie B virus infection leading to multi- organ inflammation: Myopericarditis and acute liver failure
}

\author{
Samad Zaheeruddin ${ }^{1}$, Najeebah A. Bade ${ }^{1}$, Sandeep J ani ${ }^{2}$, Monvadi B. Srichai ${ }^{2}$ \\ 1. Department of Internal Medicine, Georgetown University Hospital, Washington DC, USA. 2. Georgetown University \\ Hospital, Medstar Heart Institute, Washington DC, USA
}

Correspondence: Monvadi B. Srichai. Address: 3800 Reservoir Road NW, 5 PHC, Washington, DC 20007, USA. Email: srichai@alum.mit.edu

Received: February 7, 2014

Accepted: March 5, 2014

Online Published: March 21, 2014

DOI : $10.5430 /$ crim.v1n2p45

URL: http://dx.doi.org/10.5430/crim.v1n2p45

\begin{abstract}
Myopericarditis refers to the development of acute pericarditis with myocardial involvement. Viral infections, including Coxsackie B virus, are amongst the most common causes of myopericarditis. The Coxsackie B viruses are known to have a role in the development of a number of clinical diseases including but not limited to cardiac disease, central nervous system infections, ocular infections, pleurodynia, gastrointestinal disease, and viral exanthems. In individual cases, Coxsackie B virus may also be associated with acute hepatitis.

We describe a rare case of a 41 year-old female with multi-organ inflammation caused by Coxsackie B virus leading to myopericarditis, pleuritis, and acute liver failure. Laboratory and imaging data helped to make diagnosis of myopericarditis and appropriate management was initiated. Shortly after the patient developed acute liver failure with an INR greater than 13 and AST and ALT of $7946 \mathrm{u} / \mathrm{L}$ and $5684 \mathrm{u} / \mathrm{L}$, respectively. Viral serology revealed Coxsackie B 1, 2, and 6 serum antibody positivity ( $>1: 32$ titer) indicating acute or recent infection. A complete workup for other liver failure etiologies was negative.
\end{abstract}

The case shows the significance of awareness and recognition of the possible complications of Coxsackie B virus infection including liver failure.

\section{Keywords}

Myopericarditis, Myocarditis, Pericardits, Coxsackie B, Acute liver failure, Viral hepatitis

\section{I ntroduction}

Concomitant myopericarditis and liver failure secondary to Coxsackie virus is rarely reported in the literature. Herein we will discuss a case of a 41 year-old female who presented with classic myopericarditis and subsequently developed liver failure. 


\section{Case presentation}

Our patient is a 41-year-old female with a history of Non-Hodgkin's Follicular Lymphoma (in complete remission) and hypercoagulable state (MTHFR positive with deep vein thrombosis in past) who presents with acute chest pain.

Three weeks prior to presentation, the patient had fatigue, shortness of breath, subjective fevers, nonproductive cough, bronchospasm and myalgia. She was diagnosed with an upper respiratory tract infection and was prescribed amoxicillin, a steroid dose pack, and an albuterol inhaler. Over the subsequent two weeks she developed severe intermittent stabbing chest pain with radiation from left anterior chest into the back and left arm. The pain lasted about ten minutes per episode, did not change with exertion and improved with leaning forward. Her chest pain worsened in severity and frequency until it became persistent and unremitting, at the time she presented to the emergency room when admitted. The patient also had palpitations, orthopnea and intermittent shortness of breath; she denied any constitutional symptoms, gastrointestinal symptoms, paroxysmal nocturnal dyspnea or peripheral edema.

Family history is notable for a paternal grandfather who died of a myocardial infarction (age 62) and father with coronary artery disease status post bypass grafting (age 66). Social history is negative for cigarette smoking, drug use, alcohol use, herbals/supplements or recent travel.

Upon admission, the patient was in apparent discomfort - sitting up, leaning forward and clutching her hands to her chest. Initial cardiac, respiratory, abdominal and peripheral exam were within normal limits with the exception of notable tachypnea. Vital signs included temperature of 35.3 degrees Celsius, heart rate 63 beats per minute, blood pressure 103/56 $\mathrm{mmHg}$, respiratory rate was 20 respirations per minute and oxygen saturation was $100 \%$ on room air. Initial electrocardiogram (EKG) was unremarkable. Blood tests including serum chemistry, complete blood count and liver function tests were all within normal limits. Initial troponin-I was $1.26 \mathrm{ng} / \mathrm{mL}$ (upper limit of normal is $0.045 \mathrm{ng} / \mathrm{mL}$ ) and peaked at $1.63 \mathrm{ng} / \mathrm{mL}$. C-reactive protein (CRP) was elevated at $54.1 \mathrm{mg} / \mathrm{L}$ and INR was 2.1 (she was taking warfarin for prior VTE). Transthoracic echocardiogram (TTE) demonstrated normal left ventricular size and function without regional wall motion abnormalities or significant pericardial effusion.

A presumed diagnosis of pericarditis (vs myopericarditis) was made given the clinical presentation and aspirin therapy (975mg twice daily) was initiated, with close monitoring for signs of bleeding. Although acute coronary syndrome was considered in the differential diagnosis, given the classic signs and symptoms suggestive of pericarditis with only mildly elevated troponin in combination with therapeutic INR, a conservative approach was taken with initial medical treatment for pericarditis. Over the next day the patient's chest pain improved but she became progressively more tachycardic and tachypneic - with a heart rate up to 150 beats per minute and respiratory rate of 24 respirations per minute with an oxygen saturation of $95 \%$ on room air. The cardiac exam was significant for the development of a rub on auscultation. Repeated EKG showed sinus tachycardia, left atrial enlargement, prolonged QT interval with progression from diffuse PR depressions to diffuse ST elevations (see Figure 1). Repeat TTE showed normal cardiac chambers but new moderate sized pericardial effusion without echocardiographic signs of tamponade. Pleuritis was diagnosed with the development of new bilateral pleural effusions on chest radiograph. Concomitantly, the INR was noted to rise from 4.6 to 13.8 (2.1 on admission as patient was on warfarin). Acute liver failure was diagnosed when repeat INR was $>13.8$ and AST/ALT were 7946/5684 units/L respectively. A complete hepatitis work-up was negative, including viral and autoimmune etiologies, salicyclate levels of $<1.7 \mathrm{mg} / \mathrm{dL}$ and acetaminophen levels of $3 \mathrm{mcg} / \mathrm{mL}$. Liver ultrasound demonstrated sluggish flow through the portal veins but was otherwise normal. Subsequently, viral serologies sent on admission became available, revealing Coxsackie B 1, 2, and 6 serum antibody positivity ( $>1: 32$ titer) indicating acute infection with Coxsackie B.

In the setting of elevated liver enzymes, all the patients' medications, including aspirin, were discontinued. Colchicine was started and both tachycardia and liver function tests (see Figure 2) improved over the next few days, but the chest pain recurred. A third TTE revealed fibrinous strands within the pericardial fluid. A cardiac magnetic resonance (CMR) imaging study was performed and demonstrated findings of focal area of increased thickness in pericardium, moderate 
sized pericardial effusion inferolaterally, increased T2 signal involving basal anteroseptal, inferolateral walls of left ventricle and basal inferior wall of the right ventricle, and increased T2 signal of the visceral and parietal pericardium along the anterior, lateral, and apical inferior walls of the heart, confirming diagnosis of acute myopericarditis (see Figure 3). High dose ibuprofen and steroids were gradually added to the medical regimen (with close monitoring of liver function) leading to resolution of chest pain and orthopnea, and further improvement of tachycardia and tachypnea. On outpatient follow-up approximately one-month from discharge, repeat echocardiogram revealed complete resolution of pericardial effusion, and continued improvement in liver function tests and CRP. She required a prolonged treatment course of colchicine, ibuprofen, and prednisone taper over months secondary to recurrent chest pain.

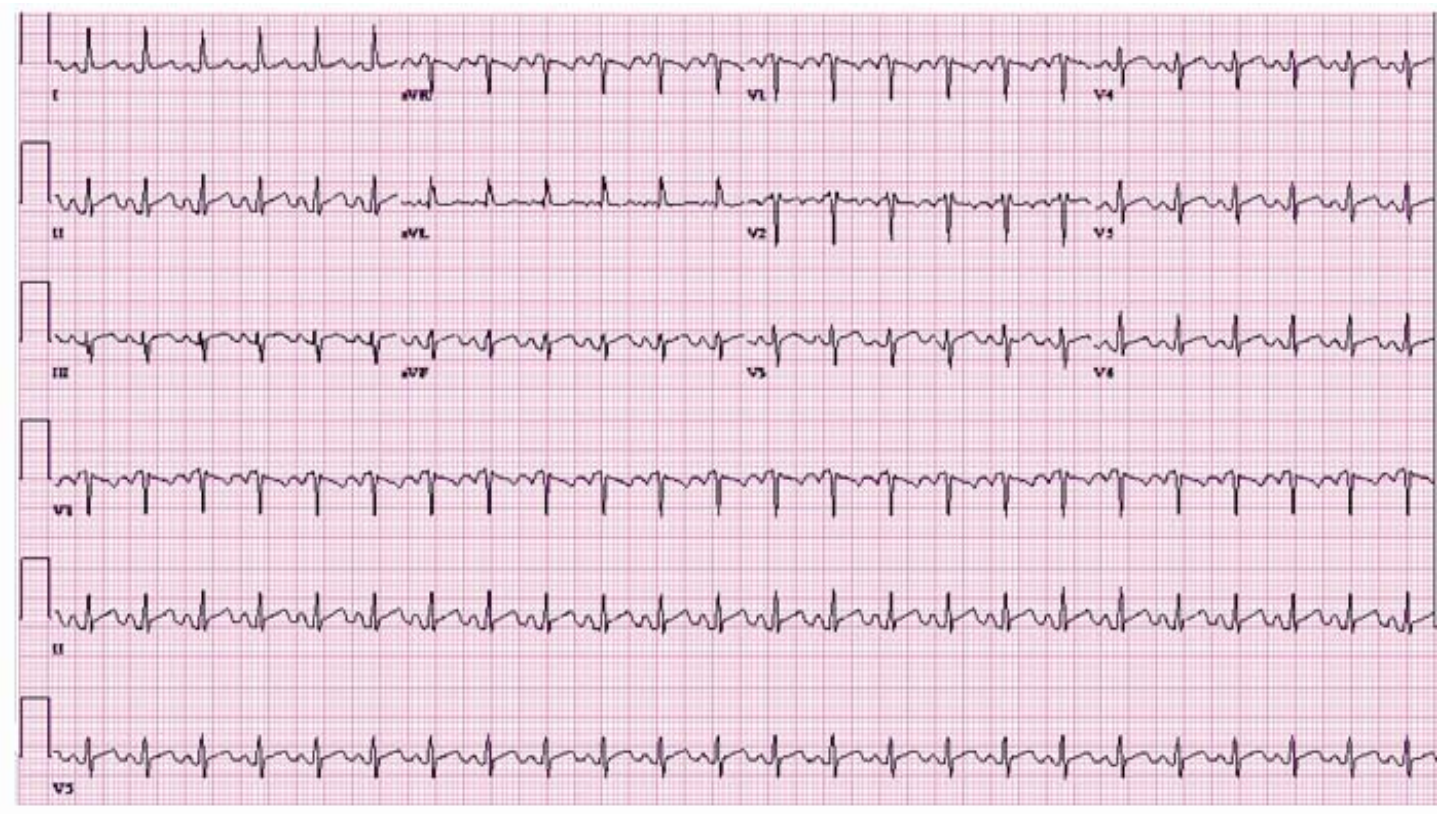

Figure 1. Electrocardiogram on Day 2 of admission. EKG shows sinus tachycardia, diffuse PR depressions, diffuse ST elevations.

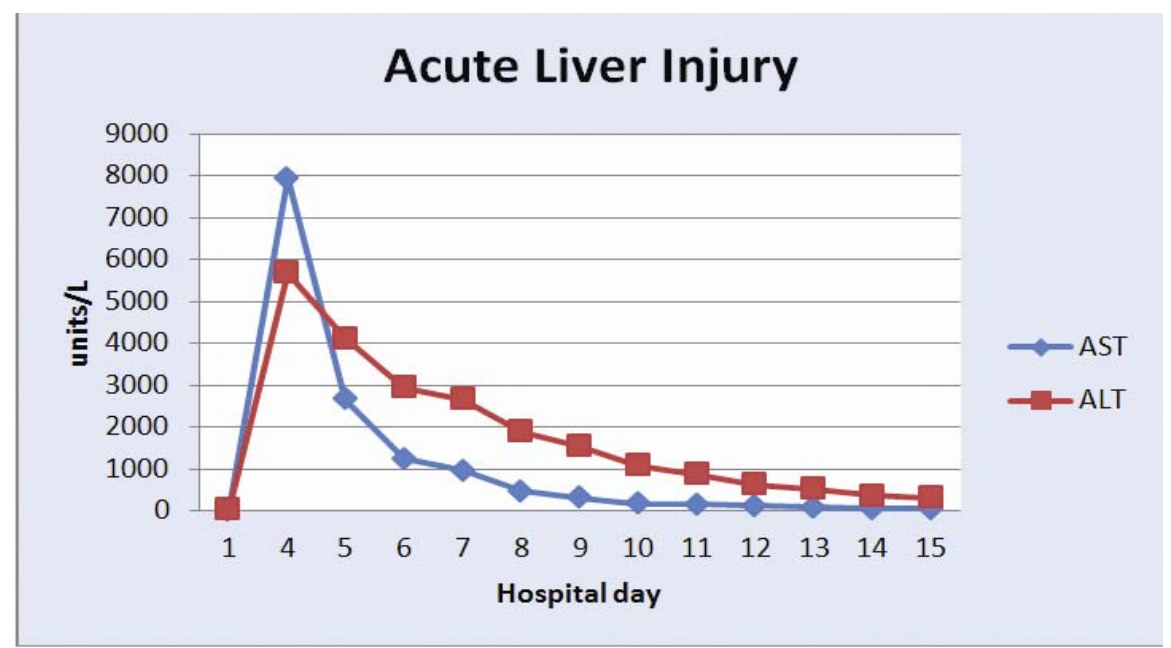

Figure 2. Liver associated enzymes through days of hospitalization. It shows the aspartate aminotransferase (AST) and alanine aminotransferase (ALT) levels throughout the patient's hospitalization. The AST peaked at 7946 units/L and the ALT peaked at 5684 units/L. Reference normal range: AST 3-34units/L and ALT 15-41 units/L 

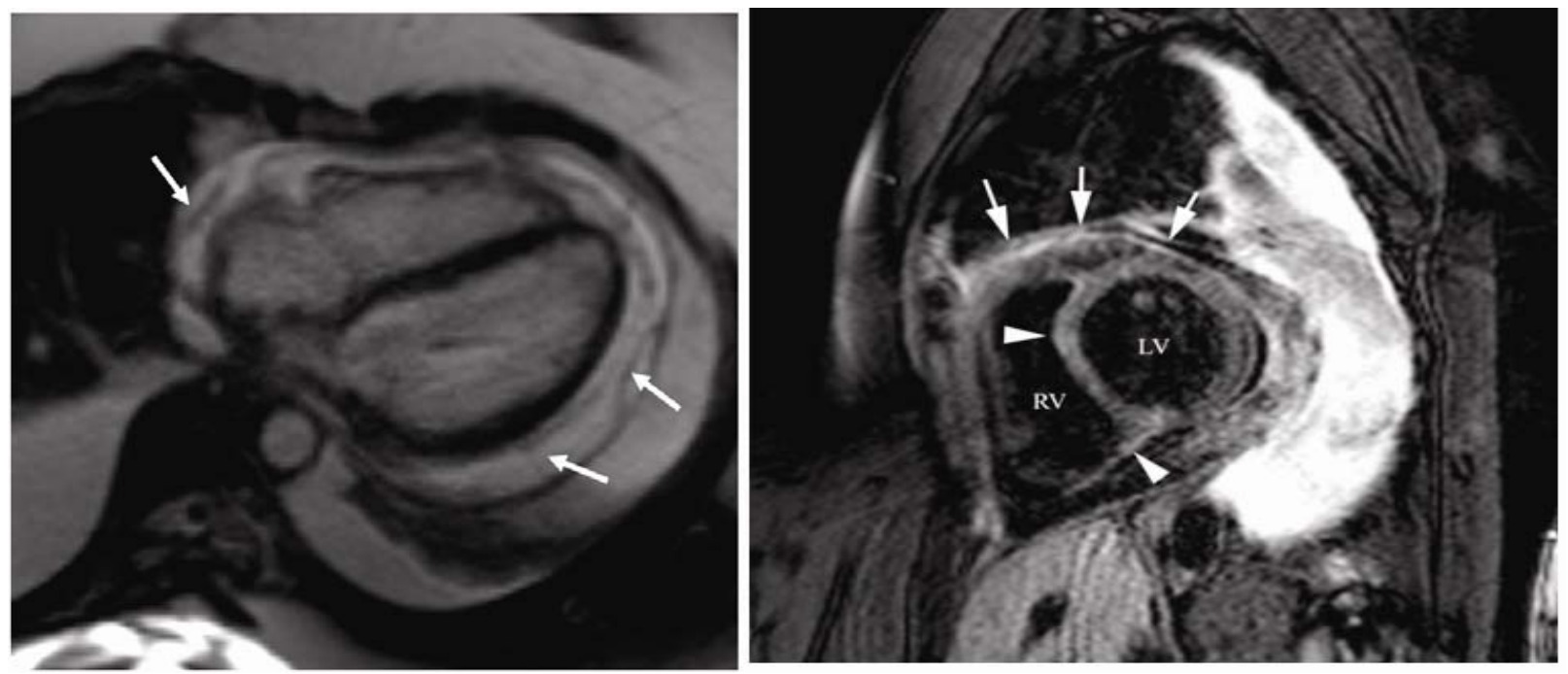

Figure 3. Cardiac MRI. A.(Left) Cardiac MRI, steady state free precession 4-chamber view of the heart, demonstrates pericardial effusion and fibrinous strands (arrows) B. (Right) Cardiac MRI, T2 turbo-spin echo (TSE) demonstrates patchy areas of increased signal (arrows) in the myocardium (arrowheads) and pericardium (arrows) suggestive of inflammation

\section{Discussion}

Myopericarditis is a rare cause of chest pain and most commonly caused by a viral etiology. Coxsackie B virus, a member of the picornaviruses, has been widely identified in the development of viral myocarditis as well as pericarditis ${ }^{[1]}$. We report a much less common presentation of Coxsackie B virus including myopericarditis and acute liver failure.

Acute pericarditis is a clinical diagnosis typically characterized by chest pain, physical exam findings, EKG changes, and pericardial effusion. In pericarditis, if a significant pericardial effusion is present, then pericardiocentesis can be performed for diagnostic purposes, but is usually only performed in the setting of cardiac tamponade or when diagnosis is in question. For myocarditis, there is unfortunately no gold standard for the non-invasive diagnosis, therefore serology for viruses and screening for auto-immune disorders are often used for diagnosis. A viral etiology is the most common cause of myocarditis (and pericarditis) and Coxsackie B virus has been identified in up to $50 \%$ of the viral myocarditis cases ${ }^{[1,2]}$. Gold standard for diagnosis is myocardial biopsy; however, given invasive nature of the procedure, serology is more widely used. CMR serves as an important diagnostic non-invasive imaging test to confirm (and exclude) suspected myocarditis given its high specificity and positive predictive value, especially within 1-2 weeks of symptom onset ${ }^{[3]}$. It can be used to identify significant ongoing inflammation, which may be especially important for patients with recurrent or persisting symptoms and in patients with new onset heart failure ${ }^{[4]}$.

Serological markers for Coxsackie B virus have been correlated with the development of myopericarditis, pericardial and pleural effusions, pericardial fibrinous adhesions, and troponinemia in case reports ${ }^{[5-8]}$. There are multiple studies describing Coxsackie positivity in patients with carditis. A Thai study (1987-1989) of 363 patients with myopericarditis revealed 19-24\% Coxsackie B titer positivity ${ }^{[9]}$.A study spanning 1972 through 1983 described 123 patients with recent upper respiratory infection and found $12 \%$ of patients to have positive titers for Coxsackie B virus ${ }^{[10]}$. Our patient developed each one of the aforementioned symptoms.

Coxsackie B virus has been described as an uncommon source of hepatitis. It has been described in the literature infrequently in individual case reports from 1962-2001 ${ }^{[11-16]}$.A case report in 2006 detailed a patient who was diagnosed with hepatitis and had a concurrent rise in Coxsackie antibody titers in the serum ${ }^{[15]}$. More recently, a report from 2009 describes a patient with hepatitis and Coxsackie A9 positivity with peak AST and ALT levels 6 days after development of 
symptoms ${ }^{[13]}$. Our patient's liver associated enzyme peak occurred 4 days after symptom onset, with severely elevated AST 7946 Units/L and ALT 5684 Units/L.

There are isolated case reports of myopericarditis secondary to Coxsackie virus, and even fewer of acute liver failure secondary to Coxsackie virus. However, there are only a few cases noted in the literature to describe Coxsackie B virus causing both myopericarditis and acute liver failure in the same patient. One case described a 16-year-old female who presented with myocarditis, liver failure, and secondary renal failure, whose AST increased to $2351 \mathrm{Units} / \mathrm{L}^{[17]}$. Another case describes a neonate presenting with acute liver failure from Coxsackie B2 virus who, upon autopsy, was found to have both myocardial and hepatic involvement ${ }^{[14]}$. Finally, a 1987 retrospective chart review of 23 patients with myocarditis or pericarditis with at least a four-fold increase in Coxsackie B titers, also had moderate to marked elevations in liver function tests. Peak levels of AST were between days 1-7 (peaking > 5000) and ALT levels were variable with marked elevation in 6 patients (peaking $>5000)^{[18]}$.

We describe a case of a young woman who developed myopericarditis and subsequent acute liver failure from acute Coxsackie B infection. To our knowledge, this is one of few case reports to describe Coxsackie B infection leading to myopericarditis with concomitant liver failure. Our case highlights the importance of clinical judgment and non-invasive testing with CMR in the diagnosis of myopericarditis. Additionally, a low threshold for screening for liver dysfunction should be maintained given the potential for multiorgan inflammation, particularly with Coxsackie B infection. The presented case shows the importance of clinical vigilance for the possible complications of Coxsackie B virus infection including liver failure.

\section{References}

[1] Feldman AM, McNamara D. Myocarditis. N Engl J Med. 2000; 343: 1388-98. http://dx.doi.org/10.1056/NEJM200011093431908

[2] Maisch B, Seferović PM, Ristić AD, Erbel R, Rienmüller R, Adler Y, et al. Guidelines on the diagnosis and management of pericardial diseases executive summary; The Task force on the diagnosis and management of pericardial diseases of the European society of cardiology. Eur Heart J. 2004 Apr; 25(7): 587-610. http://dx.doi.org/10.1016/j.ehj.2004.02.002

[3] Friedrich MG, Marcotte F. Cardiac magnetic resonance assessment of myocarditis. Circ Cardiovasc Imaging. 2013 Sep; 6(5): 833-9. http://dx.doi.org/10.1161/CIRCIMAGING.113.000416

[4] Friedrich MG, Sechtem U, Schulz-Menger J, Holmvang G, Alakija P, Cooper LT, et al. Cardiovascular magnetic resonance in myocarditis: A JACC White Paper. J Am Coll Cardiol. 2009 Apr 28; 53(17): 1475-87.

http://dx.doi.org/10.1016/j.jacc.2009.02.007

[5] Gorenbeyn A, Smally AJ. A rare case of concomitant viral myocarditis and pericarditis in a 44-year-old patient. J Emerg Med. 2004 Nov; 27(4): 355-9. http://dx.doi.org/10.1016/j.jemermed.2004.03.017

[6] Lee W-S, Lee KJ, Kwon JE, Oh MS, Kim JE, Cho EJ, et al. Acute viral myopericarditis presenting as a transient effusive-constrictive pericarditis caused by coinfection with coxsackieviruses A4 and B3. Korean J Intern Med. 2012 Jun; $27(2)$ : 216-20. http://dx.doi.org/10.3904/kjim.2012.27.2.216

[7] Matthews JD, Cameron SJ, George M. Constrictive pericarditis following Coxsackie virus infection. Thorax. 1970 Sep; 25(5): 624-6. http://dx.doi.org/10.1136/thx.25.5.624

[8] Wessely R, Vorpahl M, Schömig A, Klingel K. Late constrictive involvement of the pericardium in a case of previous myocarditis. Cardiovasc Pathol. 2004; 13(6): 327-9. http://dx.doi.org/10.1016/j.carpath.2004.07.002

[9] Dechkum N, Pangsawan Y, Jayavasu C, Saguanwongse S. Coxsackie B Virus Infection and Myopericarditis in Thailand 1987-1989. Southeast Asian J Trop Med Public Heal. 1998; 29(2): 273-6.

[10] Bell EJ, McCartney R a. A study of Coxsackie B virus infections, 1972-1983. J Hyg (Lond). 1984 Oct; 93(2): $197-203$. http://dx.doi.org/10.1017/S0022172400064718

[11] O'Shaughnessey W, Buechner H. Hepatitis associated with a Coxsackie B5 virus infection during late pregnancy. JAMA. 1962; 179: 71-2. http://dx.doi.org/10.1001/jama.1962.03050010000017

[12] Archer JS. Acute liver failure in pregnancy. A case report. J Reprod Med. 2001; 46: 137-40.

[13] Moreau B, Bastedo C, Michel RP, Ghali P. Hepatitis and Encephalitis due to Coxsackie Virus A9 in an Adult. Case Rep Gastroenterol. 2011 Sep; 5(3): 617-22. http://dx.doi.org/10.1159/000333135 
[14] Wallot M a, Metzger-Boddien C, Auth M, Kehle J, Enders G, Dirsch O, et al. Acute liver failure associated with Coxsackie virus B2 infection in a neonate. Eur J Pediatr. 2004 Mar; 163(2): 116-7. http://dx.doi.org/10.1007/s00431-003-1377-6

[15] Delic D, Nesic Z, Prostran M, Simonvic J. Anicteric hepatitis in an adult associated with Coxsackie B4 virus infection. Infection. 2006; 34: 236-7. http://dx.doi.org/10.1007/s15010-006-5004-0

[16] Gregor G, Geller S, Walker G, Campomes B. Coxsackie hepatitis in an adult with ultrastructural demonstration of the virus. Mt Sinai J Med. 1975; 42: 575-80.

[17] Read RB, Ede RJ, Morgan-Capner P, Moscoso G, Portmann B, Williams R. Myocarditis and fulminant hepatic failure from coxsackievirus B infection. Postgrad Med J. 1985 Aug; 61(718): 749-52. http://dx.doi.org/10.1136/pgmj.61.718.749

[18] Hashimoto R, Ogata M, Koga Y, Toshima H. Clinical manifestations of acute coxsackie-B viral myocarditis and pericarditis with a special reference to serum enzyme patterns and long-term prognosis. Kurume Med J. 1987; 34: 19-27.

http://dx.doi.org/10.2739/kurumemedj.34.19 